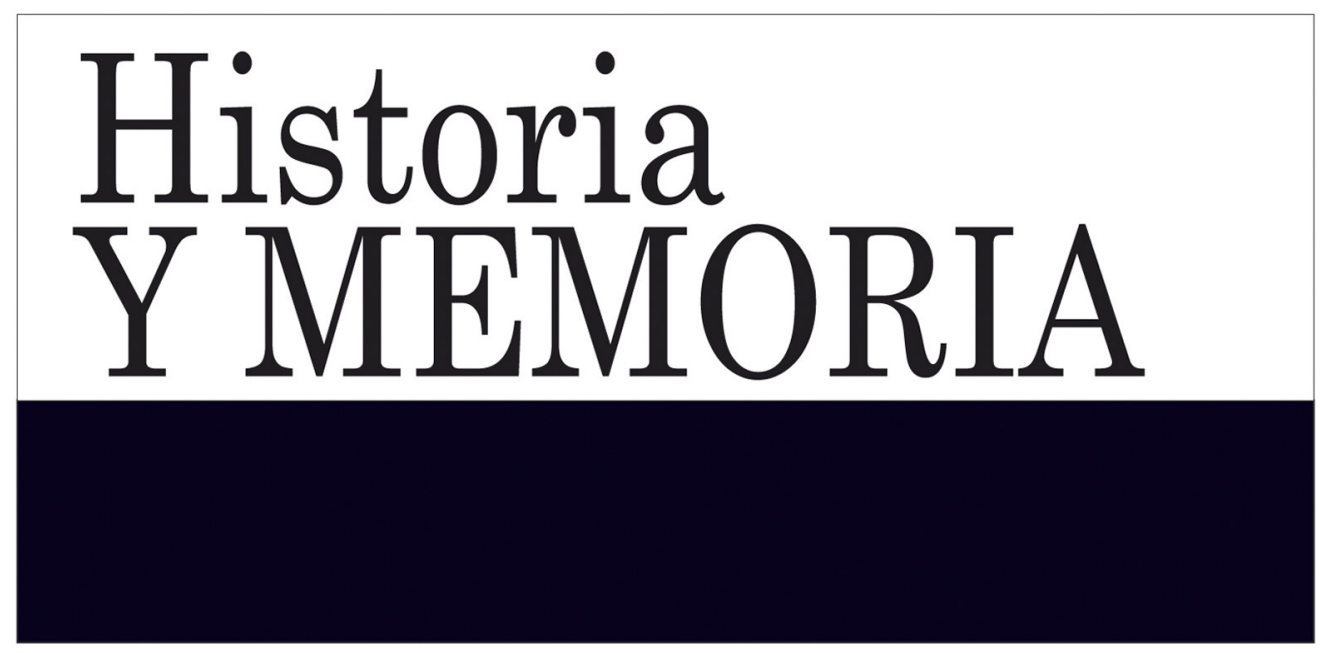

ISSN: 2027-5137 Julio - Diciembre, Año 2014 - Tunja, Colombia

Sociabilidad politica liberal de Tunja: conflictos, utopias y distopias 1843-1851

Daniel Roberto Vega Torres

Páginas: 189 - 220

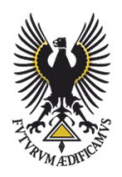




\title{
Sociabilidad política liberal de Tunja: conflictos, utopías y distopías 1843-1851*
}

\author{
Daniel Roberto Vega Torres ${ }^{1}$ \\ Fundación Universitaria Juan de Castellanos-Colombia
}

Recepción: 27/05/2014

Evaluación: 03/06/2014

Aceptación: 24/07/2014

Artículo de Investigación e Innovación.

\section{Resumen}

El artículo reconstruye la experiencia de la Sociedad de Instrucción Popular de Tunja, como una forma de sociabilidad política liberal desarrollada por abogados y notables de la ciudad entre los años 1843 y 1851. En un primer momento son presentados los conflictos políticos en que se vieron involucradas las asociaciones durante la década del cuarenta, debido particularmente a su involucramiento en disputas provinciales y estatales. En segundo lugar, se contextualiza la formalización de grupos políticos de apoyo liberal luego de la consolidación del movimiento entre 1849 y 1850 . Por último se ofrece un análisis discursivo de la Sociedad Democrática de Tunja, en cuanto hace a su sentido de pertenencia, estrategias, utopías y distopías que caracterizaron una propuesta liberal en la región a mediados del siglo XIX. Se concluye que la organización liberal en Tunja buscó aprovechar la coyuntura política para posicionar mejor ciertos proyectos e intereses de notables de la ciudad.

\footnotetext{
* Este artículo es producto del proyecto de investigación titulado: La sociedad de instrucción popular: sociabilidad política liberal en Tunja 1838-1854.

1 Sociólogo, Universidad Nacional de Colombia. Tesista de la Maestría en Historia, Universidad Pedagógica y Tecnológica de Colombia. Docente, Fundación Universitaria Juan de Castellanos. Grupo de Investigación en Pedagogía y Humanidades RELIGIO. Líneas de investigación: sociología de la artesanía, sociabilidad política. daniel.vega@ uptc.edu.co
} 
Palabras clave: Sociabilidad, Liberalismo, discurso político, Tunja.

\section{Liberal Political Sociability in Tunja: Conflicts, Utopias and Dystopias from 1843-1851}

\section{Summary}

This article reconstructs the experience of the Society of Popular Instruction, as a form of liberal political sociability developed by lawyers and other significant individuals in the city between 1843 and 1851. Initially, we present the political conflicts in which these associations were involved during the 1940's, due particularly to their involvement in provincial and national disputes. Secondly, the formalization of political groups with liberal backing is contextualized as occurring after the consolidation of the movement between 1849 and 1850 . Lastly a discursive analysis of the Democratic Society of Tunja is provided with regard to its sense of belonging, strategies, utopias and dystopias, that characterized a liberal proposal in the region in the mid-19th century. It is concluded that the liberal organization in Tunja sought to take advantage of the political situation of the time in order to improve the position of certain projects and interests of notable individuals in the city.

Key Words: Sociability, Liberalism, political discourse, Tunja.

\section{Sociabilité politique libérale à Tunja: conflits, utopies et dystopies 1843-1851}

\section{Résumé}

L'article retrace l'expérience de la Société d'Instruction populaire de Tunja, en tant que sociabilité politique libérale développée par des avocats et des notables de la ville entre 1843 et 1851. Premièrement sont présentés les conflits politiques dans lesquels ont été mêlées les associations pendant la décennie de 1840, particulièrement à cause de leur 
engagement dans des conflits au niveau de la province et de l'État. Deuxièmement, on montre la formation de groupes politiques de base libéral après la consolidation du mouvement entre 1849 et 1850 . Finalement, on analyse le discours de la Société démocratique de Tunja, du point de vue du sentiment d'appartenance, des stratégies, des utopies et dystopies qui ont caractérisé le projet libéral dans la région vers le milieu du XIXe siècle. On conclut que l'organisation libérale à Tunja a cherché à profiter de la conjoncture politique pour mieux placer certains projets et intérêts de notables de la ville.

Mots clés: Sociabilité, libéralisme, discours politique, Tunja.

\section{Introducción}

El estudio de la sociabilidad política liberal en el país se ha tomado como una parte fundamental del estudio de lo político y social fuera de las estructuras conceptuales partidistas e ideológicas de la organización social de las República en el siglo XIX ${ }^{2}$. La reflexión histórica regional contribuye a definir otras formas de abordar la comprensión de las asociaciones políticas y culturales ${ }^{3}$. Aunque los aportes generales puedan contribuir a una visión sintética del proceso, la búsqueda por explicaciones concretas puede generar visos de discontinuidades y relativas contradicciones que se entienden a la luz de objetivos puntuales. De esta manera, se puede reconocer los alcances de la reflexión social de la organización política republicana desde ámbitos menos abstractos y más relacionados a intereses y motivaciones particulares.

2 Víctor Uribe Urán, "Sociabilidad política popular, abogados, guerra y bandidismo en nueva granada, 1830-1850 respuestas subalternas y reacciones elitistas", Historia y Sociedad No. 9 (2003): 89-116; Gilberto Loaiza Cano, Sociabilidad, religión y política en la definición de la nación. Colombia 1820-1886 (Bogotá: Universidad Externado de Colombia, 2011).

3 Willian Chapman Quevedo, "Sociabilidades y prácticas políticas en Popayán, 1832-1853”, Revista Historia Caribe Vol. 13 (2008): 179-207. Oscar Guarín Martínez, "La sociabilidad política: un juego de luces y sombras", Revista Memoria y Sociedad Vol. 14: No. 29 (2010): 25-36. 
Así, para entender la sociabilidad como un conjunto de actividades continuas que cristalizan unos intereses y proyecciones compartidas ${ }^{4}$, es necesario visualizar que las asociaciones políticas se nutren de aspectos mucho más cercanos a lo interpersonal, a las contrariedades, peleas, amistades y demás vicisitudes que comprenden las relaciones humanas, de identidades y alteridades que transponen lo puramente ideológico. Aunque esto último es relevante, en este caso no enfocaré la lectura de lo político a la trascendencia de las ideas liberales, sino a las prácticas sociales que permiten la configuración y toma de posición histórico-política a mediados del siglo XIX.

Para comprender el desarrollo de procesos de creación de sociabilidad liberal de forma local, se describen tres momentos: el primero de organización de asociaciones que se proyectan como formas posibles para la toma del poder desde la configuración de propuestas articuladas con los excluidos de la nueva administración estatal a cargo de los vencedores de la guerra de los "supremos". Un segundo momento de consolidación de la Sociedad de Instrucción Popular en Tunja, como parte de las sociedades democráticas que apoyaron la candidatura de José Hilario López en los años de 1848 y 1849, esto permitió formalizar los intereses de grupos de notables de la Provincia de Tunja y de varias regiones del país en relación con grupos populares. Por último, se realiza un análisis del discurso de la Sociedad, desde las propuestas y acciones de la misma en 1850 y 1851, para concretar las manifestaciones de las políticas liberales en la región.

\section{Rivalidades políticas: Abogados y liberalismo}

Las formas de sociabilidad política se han desarrollado desde los inicios de la República en el siglo XIX. Puede afirmarse, tomando en cuenta la tesis de Loaiza Cano, que

[...] parece evidente que primero predominó una sociabilidad

4 Pilar González Bernaldo De Quirós, "La « sociabilidad » y la historia política", Nuevo mundo, mundos nuevos (2008) [En ligne], Bibliothèque des Auteurs du Centre, González Bernaldo, Pilar, consulté le 09 mai 2014. URL: http://nuevomundo. revues.org/24082. 
de élites y para las élites constructoras del mundo republicano, dispuestas por iniciativa privada a reproducir un consenso en tareas básicas del Estado, y luego se produjo la mezcla y la diversidad de prácticas asociativas que dieron origen a identidades partidistas o que al menos reunieron elementos sociales más heterogéneos. ${ }^{5}$

Así, la formación de asociaciones populares fue paralela a la construcción de la independencia, pero con unas prácticas de comunicación y con intereses aún locales y eventuales, por no decir reaccionarios. No obstante, es fundamental recordar que el tipo de sociabilidad política que se formalizó desde el notablato o las élites criollas, buscaron fortalecer la República mediante la formación de una población para el "progreso". Las bases de la ilustración que permitieron idealizar una sociedad educada en la Razón, permitieron a la vez difundir de manera clara los intereses del Estado en la formación de aspectos fundamentales como la educación, comercio, trabajo, relaciones internacionales, distracción y literatura.

Luego de los movimientos de insurrección llevados a cabo a fines de la década del treinta, en la llamada guerra de "Supremos" o caudillos regionales, la cual había dejado devastada económicamente la nación, se abrió un espacio de disputa y resentimiento mucho mayor que el percibido hasta el momento entre caudillos y el gobierno central. El frustrado plan de reorganización federal del país, con el apoyo de las sociedades democráticas organizadas para apoyar el liberalismo, agrietaba las regiones en su afán de verificar que pese al intento de centralización política, existían intereses dispares entre los grandes terratenientes, el clero, y las asociaciones de jóvenes que buscaban más poder en el gobierno con el fin de consolidar un cambio definitivo en la sociedad neogranadina. Dentro de las Sociedades Democráticas que se crearon durante fines de los años 30 en la Provincia de Tunja estuvieron la de la capital (Tunja), Soatá, Villa de Leyva y Santa Rosa ${ }^{6}$. Este tipo de asociaciones permitió la

5 Gilberto Loaiza Cano, Sociabilidad, religión...59.

6 El papel de los abogados era de gran relevancia desde fines del siglo XVIII, pues su profesionalización era significativa debido a las diferentes funciones que tenían. 
consolidación de propuestas políticas descentralizadas como el Estado Federal del Socorro ${ }^{7}$.

A pesar de las propuestas y movimientos insurreccionales apoyados por las sociabilidades liberales, con el fin de la guerra comienza un nuevo ciclo de formulación y organización política centralizada, puesto que el aplastante resultado del conflicto dejaba abierto el espacio para consolidar el gobierno centralista, luego llamado ministerial o conservador. Para Tunja, esta tendencia política se hallaba en manos de políticos como Antonio Malo ${ }^{8}$ junto con José Joaquín Gori y José Ignacio de Márquez, quienes provenían y mantenían la aristocracia tunjana de la época. Con el fin de estabilizar la provincia de Tunja, el presidente J. I. Márquez delega la función de gobernador a Francisco J. de Hoyos en diciembre de 1840 -antiguo ministro juez tribunal de distrito- ${ }^{9}$, luego de retomar el poder en el oriente. Este nuevo gobernador se inclinará por el apoyo al ejército legítimo a cargo de Herrán ${ }^{10}$ y al centralismo constitucional.

Para el año de 1842, mientras la disputa regional finalizaba en la concentración del poder con una nueva constitución, en espacios locales se dirigían otra clase de disputas igualmente significativas para la comprensión de la política regional. En carta abierta al público, el notable Carlos María Gómez exponía un caso judicial contra administradores

\footnotetext{
"The practicing lawyers fulfilled a variety of professional functions: preparing deeds and writing wills for wealthy families; designing commercial contracts between local merchants or local and foreign traders; conducting fiscal disputes, criminal cases, or litigation over dowries, entails, inheritances, donations, land, mining and property rights, and affairs of honour - one of the overriding concerns of Hispanic society". Víctor Uribe Urán, "The Lawyers and New Granada's Late Colonial State", Journal of Latin American Studies, 27, 3 (1995): 526.

7 "Estado Federal del Socorro Provincia de Tunja, Acta 2". (Tunja: Impreso por José Ayarza, 1840) Biblioteca Nacional de Colombia (BCN) Fondo Pineda (FP) 469, Fol. 87.

8 Víctor Uribe Urán, Honorable Lives: Lawyers, Family, and Politics in Colombia, 1780-1850, (Pittsburgh: University of Pittsburgh Press, 2000): 119.

9 El patriota 2, Tunja, enero 15, 1838, 1.

10 "Francisco J. de Hoyos Gobernador de la provincia de Tunja por el gobierno lejítimo de la Nueva Granada" (Santa Rosa de Viterbo: Impreso Por Vicente Baños, 17 de Diciembre de 1840) BNC, Fondo Quijano 260.
} 
de los cantones de la provincia por caso de pérdida de dineros en el correo del distrito de Boyacá en el año de 1838 en el cual él se veía inmerso. Para ese entonces él agenciaba como administrador principal de correos de la provincia de Tunja, luego de haber sido secretario del Colegio de Boyacá.

El problema se generó por una pérdida de doscientos cuarenta y tres (243) pesos en el mes de mayo de 1838, que el señor Pedro Ignacio Valderrama desde la salina de Chita dirigía a Bogotá al señor Raimundo Santamaría. La encomienda estuvo a cargo de Antonio Blanco, administrador de correos de Soatá. No obstante, la pérdida del registro de la encomienda permitió inculpar por parte de Pedro González, contratista para la conducción de correos, y el mismo Antonio Blanco, al peón conductor Laureano Niño y a Carlos María Gómez, mencionando que éste último había recibido dicho dinero. La lucha legal inició cuando González y Blanco inculparon a Gómez de hurto de la encomienda, aseverando frente al tribunal el crimen.

Al verse involucrado en el mismo, Gómez interpuso queja ante el tribunal para rectificar las declaraciones, con el resultado a su favor al encontrarlo libre de cargo ${ }^{11}$. Esta queja por injuria, es decir, por la rectificación del "buen nombre" y el honor de este administrador, permite concebir el tipo de fortalezas que alcanzaban las relaciones del notablato en la provincia de Tunja, no sólo porque recibía un apoyo del gobierno central para ese entonces de su coterráneo presidente Márquez, sino por una serie de conexiones y redes que permiten el fortalecimiento legítimo de un hombre en su cargo, es decir, la manifestación del poder e influencias locales en conflictos sobre problemas concretos. Así, por una parte se rectifica el honor de Gómez y se castiga al pago a Blanco y González, por el uso de un sistema judicial y político establecido.

El anterior caso acompañará la carrera de Carlos María Gómez al definir su inclinación política, más que por aspectos

11 Carlos María Gómez, Al público, (Tunja: Imp. de Vicente Baños, 4 de junio de 1842). Biblioteca Nacional de Colombia (BCN) Fondo Pineda (FP) 466. pza. 204 v. 
abstractos derivados de la ideología, por momentos de controversia dentro de las vicisitudes y controversias nacidas dentro de la profesión. Por ello, se tiene por bien comprender que las problemáticas acaecidas con este abogado definirán el rumbo de la política liberal en Tunja junto con Alejo Morales, quienes consolidarán las sociabilidades liberales en esta región. De este último se tiene en cuenta que su profesión no viene dada en la ciudad de Tunja, sino que inicia en el Tolima o en aquel entonces la Provincia de Mariquita. Uno de los conflictos del abogado Morales se relata en Bogotá en abril de 1845, cuando Eloi Manrique, abogado y juez natural del Tolima, acusó al juez de circuito de Garzón (Tolima), Alejo Morales, por la infracción de constitución y leyes, abuso de autoridad, detención arbitraria, prevaricato y omisión en la persecución de los delincuentes ${ }^{12}$. Los conflictos de este personaje, de igual manera, serán parte de la consolidación de la corriente liberal en Tunja, de allí que se siga su situación.

Luego de la gobernación de Francisco J. Hoyos en $1846^{13}$, se configura una organización política que defiende el "liberalismo moderado" con el cual la provincia de Tunja trató de zanjar el conflicto de los cuarenta. Esta propuesta venía acompañada del apoyo al gobierno central de Mosquera, quien habría presentado cambios de dirección política en sus últimos años del primer mandato. Dicho sostenimiento de la línea liberal se aferró en el poder provincial, no sólo en la gobernación de Hoyos, seguida de la de Plácido Morales, sino que pudo afianzar reelecciones desde la cámara provincial en la rama judicial. Para este caso, la percepción de liberalismo en el país se fortalecía como una forma de gobierno que permitía perpetuar el poder adquirido en la década del cuarenta.

12 Eloi Manrique, Espresión de agravios hecha en estrados contra la sentencia pronunciada en 1a instancia, por el Dr. Manuel Restrepo Sarasti: en la acusación intentada contra el Dr. Alejo Morales, por infracción de constitución y leyes, abuso de autoridad, detención arbitraria, prevaricato y omisión en la persecución de los delincuentes (Bogotá: Imprenta de Jesús A. Cualla. 1845). BCN-Fondo Quijano (FQ) 313. pza. 18. p. 13.

13 Francisco J. de Hoyos a los habitantes de la provincia de Tunja (Tunja, 26 de Mayo de 1841), BCN-FP 888. pza. 31. Francisco J. de Hoyos, Contestación a una carta Señores Doctores. Tunja, 9 de Junio de 1845. (Tunja: Imp. por Vicente de Baños, 1845), BCN-FP 888. pza. 34. 
Para 1848, el tribunal de justicia de Boyacá contaba con la dirección del señor Mateo Domínguez, quien con Ambrosio Gonzales y Segundo Castiblanco dirigían un círculo de poder político o club, del cual aún hacían parte aquellos compañeros de la gobernación de Hoyos y demás militares y clérigos que manifestaban ideas moderadas frente a la administración de los recursos de la provincia. Por ello se les denominaba por cierto grupo de abogados liberales como "seudo-liberales", al reconocérsele su anexión al centralismo de Herrera y Mosquera. Este afianzamiento en los tribunales como jueces de la provincia consolidó la formación de un club que se acercaba más a la manifestación concreta de la tendencia del general Mosquera en sus últimos años del primer gobierno.

Con este club se robustecieron las disputas e inconvenientes, no sólo con los problemas de una corriente conservadora, sino que además tendrá como objetivo el fortalecer de manera indirecta la constitución de una corriente liberal diferente, encabezada por Carlos María Gómez y Alejo Morales. Puesto que, derivada de las primeras acusaciones contra el abogado Gómez, la situación se desarrollará conforme éste alcanza cargos más altos, como el de ser Juez Letrado de Hacienda, adquiriendo así un poder que le permitirá de manera más concreta consolidar su ataque a los liberales moderados o ministeriales de la provincia de Tunja, acusados de ser un club demagógico que se asegura de su posición según el gobierno de turno.

De esta manera se preparaba el camino para las elecciones presidenciales de 1848, en donde el apoyo de los electores de la provincia de Tunja, que eran aproximadamente 189, tenía identificado un $20 \%$ de los votantes ministeriales del país. Estos estaban dirigidos a dos candidatos, al señor Rufino Cuervo y a José Joaquín Gori. El primero, tenía mucha más aceptación al ser natural de Tibirita (Boyacá), quién representaba para esta provincia un mejor candidato para mantener relaciones en el poder central de la Nueva Granada. El candidato de T. C. de Mosquera era el general Joaquín Barriga, los candidatos Florentino González y 
Mariano Ospina aún no tenían un alto grado de aceptación entre los ministeriales, el primero por su antigua adopción del liberalismo "exaltado", y el segundo porque aún no se había consolidado como una figura representativa, a pesar de su trabajo en los gobiernos anteriores.

Para una parte de los "liberales moderados" que aún se encontraban en los cargos públicos de la provincia, el candidato que se proyectaba era Eusebio Borrero, figura de la independencia, y quien contaba con el apoyo de una parte del notablato de Tunja. Así, en los primeros meses del año de 1848, se inició una campaña de apoyo a la candidatura de Borrero, recordando a este personaje en sus hazañas independentistas. Este militar del Cauca proyectaba para este club la oportunidad de consolidar el santanderismo que allende habían organizado en el gobierno de Márquez ${ }^{14}$. Para ellos, la elección del candidato en el mes de marzo era un objetivo relevante, pues de esto dependía la consolidación del poder regional en los cargos institucionales. Así pronunciaban la importancia que de los delegados senadores y representantes debía esperarse para la consolidación de dicha candidatura:

El $1^{\circ}$ de Marzo entrante, se reúne el $16^{\circ}$ Congreso constitucional; grandes cosas debemos esperar de este cuerpo Soberano ipleguemos al Todo Poderoso por el acierto, y tino de los escojidos del pueblo, los Representantes de la Soberanía nacional! Conciudadanos de la provincia de Tunja, ved aquí vuestros diputados, no los perdáis de vista, tenedlos presentes, para que a su tiempo les tomeis estrecha cuenta de su misión.

Senadores: Doctor Cayetano Camargo, Joaquín Larrarte, Doctor Antonio Malo

Representantes: Doctor Ciriaco Castañeda, Antonio M. Calderón, Pedro José Nieto, Severo García, Francisco J. de Hoyos, Diego Mendoza, Juan Nepomuceno Neira, Pedro Cortéz, Ezequiel Rojas. ${ }^{15}$

14 El Labrador i Artesano 16, Bogotá, diciembre 30, 1838, 60. Juan Nepomuceno Toscano, Carta al Jefe Político de Tenza (Estado Federal del Socorro, octubre 12, 1840) [manuscrito]. BCN-FP, 873.

15 “Congreso", El oteador 3, Tunja, febrero 24, 1848, 4. 
De este grupo de representantes, en los cuales se contaba con partidarios de la organización gubernamental de la provincia, estaban ligados a la propuesta de mantener las lides de la institución regional. Esto, más que una preferencia del centralismo con el cual se medía la participación política durante el cuarenta, es una reivindicación de los intereses particulares por definir esa autonomía relativa que les permitía el gobierno actual. Por ello, aunque se consideraba como una propuesta liberal, ésta se basaba más en el mantenimiento de una facción santanderista de Márquez y Hoyos, que propiamente una tendencia conservadora. De esta manera representaban al general Borrero como un candidato liberal, "la mayoría de los liberales, a los cuales pertenecen sin duda alguna los que opinan por la presidencia del Doctor Cuervo, tiene por candidato al general Borrero. Si él es el electo, los liberales son dueños del poder, así como el general Mosquera es presidente"16.

Para este grupo de notables, el liberalismo que profesaban estaba ad portas de una elección que limitaba con la tendencia gubernamental, más que una definición propia de un proyecto político consistente. La separación de este club o grupo de políticos "moderados" los llevó al fracaso en la votación, pues del candidato que apoyaban no obtuvieron ningún voto. Lo que les quitó representatividad y apoyo de los conservadores y de los liberales exaltados. Así, los 189 votos de Boyacá quedaron repartidos así: Gori: 63; Cuervo: 110; Ospina: 0; Barriga: 13; González: 3; Borrero: 0.

Por el lado de los liberales "exaltados" o aquellos que se habían visto derrocados en la guerra de los "supremos", apoyando a Obando y López, encontraban en éste último, el general José Hilario López, al candidato pertinente para ser impulsado por distintos grupos de electores, como los estudiantes de colegios, la Sociedad Democrática de Artesanos en Bogotá ${ }^{17}$-que nuevamente se había consolidado para ir

16 "Candidatura para la presidencia Jeneral Eusebio Borrero", El Oteador 5, Tunja, marzo 19, 1848, 2.

17 Carmen Escobar Rodríguez, La Revolución Liberal y la protesta del artesanado (Bogotá: Fundación Universitaria Autónoma de Colombia, 1990). Enrique Gaviria 
en contra de las disposiciones económicas propuestas por Mosquera y González- y alguna parte de notables que veía necesario reivindicar el liberalismo en la Nueva Granada al considerar opresivo el gobierno centralista fortalecido con la constitución de 1843.

Luego de que ninguno de los candidatos de la elección del primero de agosto de 1848 hubiese resultado vencedor, se procedió a definir por parte del Congreso al nuevo presidente. Para el 7 de marzo de 1849, la votación daba como vencedor en las urnas a López después de cuatro oportunidades en que los 84 electores del congreso dieron como vencedor al general liberal sobre su contendor Cuervo, recibiendo el primero 45 votos, mientras que el segundo tuvo 37 votos. Lo que se pueda considerar sobre la manera en que los votos favorecieron a López en contra de las expectativas que se tenían, produjo un gran cambio tanto en los notables del país, como en la población granadina en general. Esta elección permitirá entender por qué los "seudo-liberales" se encontraron con un nuevo escenario político que fortaleció el liberalismo exaltado, que había sido derrotado a inicios de la década del cuarenta; pero a la vez entender que las adhesiones a los cambios liberales se verán fortalecidas.

\section{La construcción de la Sociedad Liberal de Tunja}

Al promulgarse un nuevo levantamiento del poder liberal a fines de la década del cuarenta, constituido por juventudes universitarias instruidas en las ideas políticas europeas, se organizan sus adeptos para consolidar proyectos económicos y políticos con el apoyo de otros sectores sociales, en especial los artesanos. Entre estos jóvenes se encuentran Salvador Camacho Roldán, Miguel y José María Samper, Rafael Núñez, Santiago y Felipe Pérez, entre otros, dirigidos ideológicamente

\footnotetext{
Liévano, El liberalismo y la insurrección de los artesanos contra el librecambio. Primeras manifestaciones socialistas en Colombia (Bogotá: Universidad Jorge Tadeo Lozano, 2002). Jaime Jaramillo Uribe, "Las sociedades democráticas de artesanos y la coyuntura política colombiana de 1848", en: La personalidad histórica de Colombia y otros ensayos (Bogotá, Biblioteca Básica Colombiana, Colcultura, 1977). Renán Vega Cantor, "Liberalismo económico y artesanado en la Colombia decimonónica", Boletín cultural y bibliográfico, 22 (1990).
} 
por Ezequiel Rojas, Florentino González, Lorenzo María Lleras y Manuel Murillo Toro. De esta formación se organizará la corriente liberal que tendrá de por sí mutaciones y cambios constantes a lo largo de todo el siglo, aspecto que se diferencia de la corriente conservadora la cual presentará una mayor continuidad y homogeneidad.

El papel de los artesanos se convertirá en algo fundamental para dicho proceso. La identificación del artesanado durante casi todo el siglo XIX estará destinada al reconocimiento y participación política. Es decir, no parece relevante la constitución del artesanado dentro del oficio sino dentro de la conciencia de grupo que definiría la dinámica de las organizaciones artesanales ${ }^{18}$. Los artesanos que participarán de nuevas formas de agrupación estarán más relacionados con las ciudades y centros políticos de provincias. "El artesano libre, huérfano de una estructura organizativa, encontró otras formas de sociabilidad, de carácter social, religioso o político, primero pensadas desde la ayuda mutua, la defensa y la ilustración -Sociedades de Artesanos-y después con carácter más participativo y beligerante-Sociedades Democráticas-"19.

La disposición del nuevo panorama político permitió una acción con un horizonte nacional en la creación de redes políticas de sociedades, y a la vez tuvo implicaciones regionales en la configuración de los poderes administrativos de las provincias. Para el caso de Tunja, la pérdida de apoyo de los ministeriales al fracasar en la elección de su candidato, permitió una ofensiva de los liberales exaltados; esta se dio desde la toma de poder en la administración de justicia con el posicionamiento de gobernador y alcaldes.

El 15 de mayo de 1849, el Tribunal de Distrito de Boyacá nombra al Sr. Carlos María Gómez ${ }^{20}$ como Ministro

18 Francisco Gutiérrez Sanín, Curso y discurso del movimiento plebeyo 1849/1854 (Bogotá: El Áncora Editores, 1995), 28.

19 Luis González Escobar, Maestros y artesanos en la arquitectura de Medellín y Antioquia 1775 - 1932 (Medellín: Universidad Nacional Facultad De Arquitectura, 2008), 92.

20 Cabe recordar que según bajo el Gobierno de José Hilario López, se expide la 
Juez "para complementar la sala de acuerdo, por hallarse con licencia uno de los Ministros jueces, i al Dr. Ricardo Monroi para Secretario interino del mismo Tribunal. El día 22 al Dr. Luis Reyes ${ }^{21}$ para completar la sala de acuerdo por el motivo expresado"22. En este sentido, se comienza a gestar un proceso de apoderamiento y fricción. Luego de la posesión de Carlos Gómez, la situación política estaba dispuesta sobre dos polos de intereses grupales: por un lado se encontraba el club ministerial encabezado por los ministros reelectos Domínguez y González, y el séquito de abogados, clérigos y militares que había acompañado los gobiernos provinciales de Hoyos y Morales; y por el otro, una tendencia cercana a la preferencia "exaltada" nacional de López y Obando, encabezada por los abogados Carlos María Gómez y Alejo Morales.

Así, entendiendo que sobresalen las estrategias asociativas que se producen en función de intereses interpersonales y de adhesión a las propuestas gubernamentales del liberalismo, es como se puede iniciar una observación de los problemas políticos de la región. El caso de Carlos María Gómez es significativo, pues sobre él se desarrollan las sinergias de asociaciones durante el año de 1849. Cuando llega a su cargo como ministro juez en el tribunal de Boyacá, se inicia una acción de desprestigio por parte de aquellos que veían vulnerado su poder en esta institución. El ataque también concierne a Francisco de Paula Bermúdez, ambos recién electos en los cargos, aunque hayan participado de gobiernos anteriores en oficios distintos, mantuvieron sus reservas de dichas administraciones.

Ley 28 de Abril 10 de 1849 "Sobre tratamiento oficial a los funcionario públicos", la cual decreta que: Al Presidente y Vicepresidente, a los presidentes de la cámara legislativa y a los generales del ejército se le dirá Ciudadano, "A los demás funcionarios i empleados públicos se les dará el tratamiento de Señor antepuesto al título del empleo". José Antonio De Plaza, Apéndice a la recopilación de Leyes de la Nueva Granada (Bogotá: Imprenta del Neogranadino, 1850), 14.

21 Personaje en los años de 1860, bajo una postura federalista, insistiría en la resistencia de la toma de los estados de Boyacá y Santander bajo el gobierno conservador de Ospina. Tomás Cipriano De Mosquera, Discurso del presidente provisorio de los Estados Unidos de Colombia, en la instalación de la Convención Nacional. (Bogotá: Imprenta de Echeverría Hermanos, 1868): 18.

22 Gaceta oficial 1058, Bogotá, julio 1, 1849. 
Este caso de descrédito frente a estos dos abogados presentado a la Corte Suprema y al Gobierno de la República por parte de quienes se autodenominaban como "Todos los liberales de la provincia de Tunja", permite visualizar que al "inmiscuir" dos personas fuera del club de Domínguez y González acarrearía la disputa para expulsar aquellos personajes de la vida pública. La aparente contravención que se le imputaba a Gómez venía de su problema judicial iniciando una década atrás por proceso judicial en su contra. De este hecho se le adjudicaba la falta de capacidades para conducirse en el ministerio. En réplica a ello, en publicación impresa "muchos liberales de la provincia de Tunja, i no falsos" declaraban su inconformidad a esta situación y apoyo a estos abogados.

Según este documento, el trabajo de descrédito para con los abogados era impulsado por Domínguez, González y Castiblanco, a quienes se les reprochaba ser liberales por conveniencia ${ }^{23}$. El problema, según los defensores, surgió porque Gómez vino a reemplazar el puesto de Francisco de Paula Angulo, quien era parte del grupo ministerial. En respuesta a esas acusaciones, los liberales exaltados respondían que

Las manchas que para ustedes tiene el doctor Gómez, son las de la virtud i de la ciencia [...] i ustedes dicen que es como el camaleón (plajio, i que se les ha dicho a ustedes) porque juzgan por su condición; mas él ha sido liberal desde antes del 7 de marzo, i ustedes, señores oposicionistas, ¿qué han sido, son i serán? [...] Siempre ministeriales i partidarios del que manda i les da destino. ${ }^{24}$

La división de estos tipos de asociación autodenominados liberales-unos "moderados" y otros "exaltados"-se reproducirá en los ataques que se llevarán a cabo durante el año de 1849, con apoyo del fiscal Alejo Morales. Como era de esperarse, el conflicto se desarrolló en función de la representación e imaginario legalista y constitucional. En marzo de 1849,

23 Carlos María Gómez, Al público, Tunja, 1848 BCN-FP 815, pza. 9.

24 Carlos María Gómez, Al público... 
iniciado un proceso por parte de Morales contra los ministros de la Corte Suprema de Justicia, “(...) por habérsele mandado seguir causa de responsabilidad por faltas en el cumplimiento de sus deberes (...)"25. Se podría mencionar a este como uno de los primeros conflictos que van a nutrir las disputas políticas de aquel año en la provincia de Tunja. El conflicto judicial involucra al fiscal Morales con el Sr. Mateo Domínguez, pues se le acusaba por parte del primero de haber faltado a sus obligaciones al no haber recibido unas pruebas en un juicio contra Encarnación Huertas, vecino de Tibaná, por haber supuestamente extraído éste unos documentos del archivo de dicho pueblo.

Junto a este primer conflicto, en los meses siguientes del año se presentarán otros juicios que involucrarán a los ministros Carlos González y a Mateo Domínguez. Puede entenderse más que como unos hechos aislados, una serie de sucesos intencionados y, en cierta medida, coaccionados. En septiembre de 1849 se encuentra la primera sentencia de un juicio contra Carlos González, en donde se le imputa el cargo de omisión, por "no haber en la sentencia de segunda instancia que pronunció en la demanda instruida por Rafael Vela contra Rufino Martínez sobre intereses, que el Sr. Juez de la primera instancia procediere contra los testigos José María Aconcha y Julián Cancino por el delito de perjurio" al dar declaraciones contradictorias.

Para junio del mismo año, encontramos un juicio promovido por Carlos María Gómez contra Mateo Domínguez y Carlos González, quienes revocaron la sentencia en segunda instancia del juicio contra José María Medina Celi, que llevaba a cargo el Sr. Gómez por calumnia e injuria. El proceso judicial parte de un conflicto pasado en segunda instancia en donde se acusa a Gómez por una supuesta intención de desvirtuar el proceso contra José María Medina por haber declarado tener el Sr. Gómez un odio a la familia del acusado. No obstante, a él también se le acusó por haber alterado dicho proceso al modificar las declaraciones de Medina.

25 "Resultado de un denuncio contra los ministros de la corte suprema" Gaceta Oficial 1041, Bogotá, mayo 3, 1849): 162. 
También aparece una acusación de José Domingo Sánchez contra el ministro juez Mateo Domínguez fechada en inicio por parte de José Miguel Sánchez ${ }^{26}$. Reiterando la problemática que se encuentra dentro de las esferas judiciales del Distrito durante la segunda mitad del año de 1849. Por último, encontramos un proceso que se realiza en contra del ministro juez del Tribunal Superior del Distrito de Boyacá Dr. Carlos González, a quien se le acusa de haber mandado acumular unos autos en contra del juez letrado de Villa de Leyva, Dr. Isaac Orjuela, por delitos de prevaricato y rebelión, juicio que llevaba el ministro del mismo tribunal Carlos María Gómez. Se le reconoce al Sr. González que no debió interferir en el juicio que ya había iniciado el Sr. Gómez, y que no tenía autoridad superior para revocar ni intervenir en proceso de un igual, puesto que un principio del derecho reza que "el igual contra el igual no tiene imperio" 27 .

Lo que se puede percibir de los juicios anteriores es que detrás de cada uno de los procesos estaba incluida la necesidad de conformar un bloque sólido en el poder desde el cambio gubernamental con José Hilario López. Se entiende el esfuerzo por separar a algunos individuos de los cargos públicos por mantener una nómina de funcionarios que fuese en pro de los intereses generales del gobierno central. Así, junto a las visibles disputas de notables de la Provincia de Tunja, se lleva a cabo un cambio significativo en las propuestas gubernamentales que fueron consolidando las asociaciones políticas liberales en varias regiones de la Nueva Granada. Estas asociaciones políticas se anexaron a la Sociedad Democrática de Artesanos de Bogotá reconstituida en 1848.

La noche del 16 de noviembre de 1849, mediante la reunión de un grupo de "ciudadanos que profesan por convicción los principios liberales" se crea la Sociedad de Instrucción Popular de Tunja. El objetivo de dicha sociedad

26 "Contra el Dr. Carlos González Ministro Juez del Distrito Judicial de Boyacá", Asuntos Criminales de la República: Sección República, 12. 1849. Fol. 885 v. Fol. 898 r. Archivo General de la Nación (AGN).

27 “Contra el Dr. Carlos González, Ministro Juez del Distrito... Fol. 901 v. 
era "propender con mayor ahínco, a que se difundan las luces, a que el pueblo se instruya, por consiguiente en sus derechos i obligaciones, i a que adquiera perfecto conocimiento de los principios liberales i democráticos, únicos i exclusivos que pueden hacer la felicidad de nuestra cara patria"28. No sorprende pues, que el conflicto entre iguales no haya acaecido por una simple casualidad personal, sino que el proyecto político también se manifestó en los pasillos de los Tribunales del distrito de Boyacá, siendo escenario principal para ejercer el control liberal que sustentará la siguiente década en cuanto a proyectos sociales y políticos.

Los firmantes de esta Sociedad son: Joaquín Machado, Ramón Acevedo, Fruto Vélez, José María Buitrago, Ignacio Franco Pinzón, Rafael Vela, Gregorio Páez, Jesús Díaz, Domingo Casas, Buenaventura Larrota, Dimas Arias, Torcuato Borda, Ignacio Sierra, Juan N. Villate, Juan Jaime, Fernando Higuera, Antonio Flores, Sebastián Jaime, Francisco de P. Angulo, Pedro Roncancio, Juan N. Osuna, Antonio María Amézquita, José Primo Rojas, Telésforo de los Ánjeles, José Rudecindo Carvajal, Nicolás Machado, José María Solano, Carlos María Gómez, Alejo Morales i Vicente Torres. El secretario de la Sociedad Carlos María Gómez ${ }^{29}$. Para 1850, luego de la creación de la Sociedad de Instrucción Popular, se adhieren más simpatizantes de la figura del general José Hilario López ${ }^{30}$.

Una forma de entender este tipo de identidades y adhesiones es mediante la pertenencia a los diferentes factores del proceso de formación liberal, configurados en cuatro momentos representativos. El primero, la creación de sociedades democráticas en 1838; el segundo la participación en la organización del Estado Federal del Socorro en 1840; el tercero, en la consolidación y apoyo al gobierno de F. J. Hoyos

28 "Sociedad de Instrucción Popular", Gaceta oficial 1089, Bogotá, diciembre 2, 1849,550 .

29 "Lista de los Ciudadanos que concurrieron a la instalación de la 'Sociedad de Instrucción Popular' en la capital de la provincia de Tunja", Gaceta oficial 1089, Bogotá, diciembre 2, 1849, 550.

30 "Ciudadano Presidente de la República", La Libertad 8, Tunja, junio 1, 1850. 
en 1845 y por último la adhesión al gobierno liberal de J. H. López en 1849.

En primera medida observamos que de aquellos que participaron en la organización de la Sociedad Democrática de Tunja en 1838 se unían una década después a la Sociedad de Instrucción Popular: Ignacio Leal, Juan Nepomuceno Rojas, Lucas La Rota, Manuel Ruiz, Nicolás Machado, Rafael Machado, Segundo Castiblanco y José Gregorio Páez ${ }^{31}$. Todos ellos notables de la ciudad de Tunja, que en uno u otro caso pueden considerarse como partícipes de la corriente santanderista liberal y republicana.

En segundo lugar, podemos identificar aquellos que colaboraron a la construcción del federalismo en el oriente durante 1839-1840, entre ellos encontramos al militar Dimas Arias, Joaquín Torres, José Gregorio Páez, Manuel Ruíz, Rafael Machado, Sebastián Jaime y Timoteo Rivadeneira ${ }^{32}$. Debe destacarse la continuidad de Páez y Machado, pues durante la organización del Estado Federal estuvo más cercano el proceso militar de sustentar el nuevo proceso independentista.

Luego, encontramos a quienes de alguna manera, apoyaron el gobierno constitucionalista y, en cierta medida, liberal-moderado de Hoyos. En este caso encontramos a Carlos Gutiérrez, José Primo Rojas, Juan Nepomuceno Rojas, Juan Nepomuceno Villate, Patrocinio Cuéllar, Proto García, Ramón Escovar, Segundo Castiblanco y Vicente Azula ${ }^{33}$. Estos tres momentos de actividad política son divergentes en la manera como se proyectaba la sociabilidad, pues confluía en el primero un proyecto relativamente consolidado, que fue el santanderista, un paso de adhesión militar y caudillista en el segundo, y un proceso político flexible y de conveniencia regional en el tercero. Dichos aspectos comprueban la

31 El Labrador i Artesano 17, Bogotá, enero 6, 1839, 65.

32 El Labrador i Artesano 17...65.

33 "Sr. Doctor Francisco José de Hoyos", Tunja, junio 1 de 1845 (Tunja, Imp. por Vicente de Baños, 1845) BCN, Fondo Pineda 873. Fol. 173 r. 
variabilidad de los tipos de asociación, pero en la misma forma consolida los tipos de agrupación liberal que se desarrollan en la provincia de Tunja durante una década.

\section{Utopías y Distopías: actores y discursos políticos}

Para entender la manera como se desarrolla la Sociedad de Instrucción Popular desde sus intereses, comunicaciones y propuestas que permitían consolidar una actividad continua, es pertinente retomar el análisis metodológico de Francisco Gutiérrez Sanín. Este autor nos presenta una propuesta que nos conduce a analizar el discurso de las asociaciones políticas de mitad de siglo en cuatro aspectos:

1. Buscar mediante testimonios sentidos de pertenencia a partir de los cuales se articulan y desagregan los actores sociales.

2. Encontrar cuáles son sus estrategias, valores y propuestas.

3. Hallar cuáles son los actores que defienden modelos o programas de la sociedad futura, es decir, describir los tipos de sociedad que buscan utopías, a la vez observar las distopías o peores futuros posibles.

4. Identificar la dimensión orgánica y espacial de dichas estrategias, utopías y distopías ${ }^{34}$.

Vamos a pasar a explicar mediante este tipo de planteamiento la Sociedad de Instrucción Popular, tanto en los actores, su discurso, sus prácticas y el espacio social de enunciación desde donde se proyectaban. Según Gutiérrez Sanín, un rasgo característico de los actores o integrantes de las asociaciones políticas - para su estudio "plebeyas"-, tiene de por sí dos hipótesis: la existencia de varios tipos de pertenencia y la volatilidad de los individuos en las organizaciones ${ }^{35}$. Para el caso de la Sociedad de Instrucción Popular, revisaremos

34 Francisco Gutiérrez Sanín, Curso y discurso...26.

35 Francisco Gutiérrez Sanín, Curso y discurso...29. 
este tipo de premisas que pueden tomarse en cuenta como formas de participar asociativamente en una práctica política o en la distribución de formas de poder mediante el gobierno regional. Puede observarse que la identidad e identificación principal se daba en base a la adherencia de los miembros al liberalismo, impulsado desde el cambio gubernamental en cabeza del general López. Pero para desarrollar la identificación observemos, de igual manera, el grado de continuidad o volatilidad que ha tenido esta identidad liberal.

El sentido de pertenencia para agrupar es la capacidad de consolidar formas de asociación que respondan a proyectos relativamente autónomos pero que trascienden a intereses generales de autonomía en el gobierno, mayor desarrollo de mecanismos gubernamentales en lo económico y lo fiscal, redistribución de las tierras y resguardos, entre otros. Pero estas tendencias no pueden estar separadas de una trayectoria o centro de sacralidad de la población granadina, la formación de la República, ese es el escenario de agrupación de políticas por parte de liberales o "seudo-liberales".

Para ocuparnos de las estrategias de asocio o sentido de pertenencia de agrupar, se encuentra la propuesta ilustrada de "iluminar" o civilizar el camino de la república mediante la razón. Los integrantes de la Sociedad de Instrucción Popular permiten diferenciar aquellos individuos que estuvieron con el liberalismo de aquellos que apoyaron los gobiernos de Márquez, Herrán y Mosquera. Este tipo de asociación se centraba en enaltecimiento de la sociedad liberal republicana, mientras que las estrategias de disociación o sentido de pertenencia para disociar, se encaminan a consolidar a los "enemigos" como los conserveros, conservadores, que impulsaban mantener la dominación en condiciones semejantes a la colonia. El sentido independentista se aferra a los pocos cambios que habían acaecido desde la separación de la corona española, esa disociación que ponía en contra todo rezago colonial fue un factor que se aprovechó para poner límites y fronteras a las representaciones políticas de la región.

Se retoma una forma de identificación temporal y espacial, pues no sólo reafirma la participación de los liberales 
en la provincia de Tunja, sino que además organiza una periodización diferente a la llevada desde la independencia para enfrentar un proceso autónomo y teleológico de la vida republicana. El discurso victorioso es frecuente en las publicaciones de esta asociación, en especial si retomamos la manera como se observa una teleología del movimiento hacia un "progreso". En la primera editorial de su medio de publicación La Libertad, se hace notorio este aspecto:

Contrayéndonos a la Nueva Granada hallamos que en los 23 años transcurridos desde 1810 hasta 1833 fue la época de los valientes, de los sacrificios, del patriotismo - De 1833 a 1837 la mui corta pero resplandeciente era de la instrucción i de los sanos principios - I los 12 años terribles desde 1837 hasta 1849, la demasiado larga de las persecuciones, de la inseguridad, de la irrupción de todas las calamidades que pueden aflijir la sociedad. Desde el $1^{\circ}$ de Abril de 49 empieza la era de la libertad i de la práctica de los principios democráticos. ${ }^{36}$

Como observamos, existe un tipo de periodización que conduce a presentar a la opinión pública que su llegada al poder era necesaria, que se justificaba no sólo por la liberación de un grupo de personas destinadas a la conservación de un gobierno coercitivo e impositivo, que atentaba contra la libertad, en este caso de asociación, tribuna o imprenta. Esto referido a las fuertes políticas que se habían impuesto a la población luego de los "desórdenes" que atentaban contra la República y la Constitución en la guerra de los tres años o de los "supremos".

Son este tipo de defensa a las libertades las formas de poder identificar a quiénes cumplían con los rasgos liberales que se basaban en la corriente de "exaltados". De esta manera agrupaban a mayor número deindividuos a propuestas tomadas de la agenda liberal de mitad de siglo y que se desarrollaban en varios intereses ilustrados y civilizadores como lo presenta la citada editorial, continuando de la siguiente manera:

36 "Editorial", La Libertad 1, Tunja, abril 1, 1850, 1. 
No exajeramos, pues; no nos mueve el espíritu del partido cuando aseguramos que el $1^{\circ}$ de Abril de 1849, empezó la era de la libertad que se estiende hoy a todos los puntos de la República no podía dejar de ejercer su benéfica influencia en la provincia de Tunja. En efecto, la sociedad actual, no es en ella, i particularmente en esta ciudad, la sociedad de ahora un año. Las costumbres son buenas como antes; pero están mas de acuerdo con la cultura i las ideas del siglo. La franqueza i las buenas maneras están reemplazando el triste cuanto ridículo tono aristocrático, que aunque en miniatura, se pretendía hasta ahora poco tiempo sostener. [...] Últimamente se pretende mejorar la mala imprenta que hai en la ciudad i se escribe un periódico liberal. Abril $1 .^{37}$

Se concibe un cambio general en la sociedad granadina, se hace punto de inflexión en la historia mediante nuevas trayectorias, cabe recordar que el tono de conquista no implica la negación del otro en relación de la dicotomía bueno/ malo, es decir, no se intenta oscurecer el pasado de una manera totalizante. En otras palabras, no se iba a las bases de la estructura que distribuía y organizaba a la población granadina, sino que se enfocaba en él como se había hecho durante la década anterior. Pero si bien no se encuentra una disociación total a la estructura, como otros tipos de propuestas socialistas o comunistas que pálidamente llegaban en esos años, sí se dirigían lanza en ristre contra el grupo opuesto, es decir el partido "godo-conservero", quién había victimizado diversos grupos de población en el país, así lo expresaban y reproducían en el aniversario del 7 de marzo:

Esperamos de la providencia, i de la buena marcha que lleva la opinión pública, que vendrá un día de verdadero escarmiento para los conserveros, escarmientos que piden tantos asesinatos cometidos por ello con el fin de que no se conservaran los principios de libertad i progreso...

Llegará, tenemos fé en nuestras creencias, i confiamos en nuestro valor, porque egrejios varones, como López y Obando, aún viven para nuestra salud, aún viven para desgracia y terror de nuestros enemigos. Ellos curarán las dolorosas heridas que aún no están cicatrizadas.

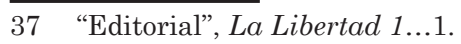


[...] Esperad ladrones de la República que el día llegará, i para entonces pedid a Dios resignación para sufrir. Cartagena 7 de Marzo de $1850 .^{38}$

Este tipo de descripción de la victimización de la población, refleja el tipo de distopía que fortalece el discurso liberal, es el de tener seguridad que el futuro que se espera en manos del partido "godo-conservero" se limita a la reproducción de los homicidios, represiones y amenazas que se habían presentado en su gobierno, de allí que este panorama obligaba a definir un rumbo más consolidado en el castigo, divino o humano, que deberían tener por haber puesto a los granadinos en dichas condiciones.

El fortalecimiento de la Sociedad de Instrucción Popular, entonces, recorre varios aspectos, entre ellos: primero, el afianzamiento de los cargos públicos por parte de los integrantes de la misma; segundo, mediante las incursiones de estos en la política nacional, y por último la opinión de un liberalismo que contribuye a uno de los centros principales de las costumbres y el imaginario tunjano: la religión católica. Para el año de 1850 el gobernador de la provincia era el integrante de la Sociedad de Instrucción Popular, Patrocinio Cuéllar, quien también era parte de la logia masónica del país ${ }^{39}$. El aporte a la rama gubernamental de la provincia estaba ya definida con este cargo, del cual se fortalecía no sólo el cantón de Tunja sino el de los demás cantones de la provincia. El apoyo a la gobernación de Cuéllar se profesaba como parte del sentido de pertenencia para agrupar a los sectores diversos de la población, en cartas remitidas de algunos ciudadanos de los cantones de Miraflores, Garagoa y Guateque, se observa cómo dentro de la población existía un respaldo al mantenimiento del cargo:

El ciudadano PATROCINIO CUÉLLAR entre otras cualidades reúne las del don administrativo, prudencia e imparcialidad- Él se ha granjeado en la provincia

38 "El 7 de marzo en la Nueva Granada", La Libertad 1, Tunja, abril 1, 1850, 3.

39 Jaime Tovar Borda, Radicales, religionarios y artesanos, sociabilidad y política: Bogotá 1855-1870 (Tunja: UPTC, 2005). 
grandes simpatías, i estimación personal, i tiene un pleno conocimiento de la mayor parte de los hombres influyentes de ella: con tales elementos su posición como gobernante es mui ventajosa, los negocios públicos marchan por el carril de la lei, i los intereses del verdadero progreso caminan a la cima de su perfección. El actual Gobernador goza de una completa popularidad en los cantones del Sur de la provincia de la que sabemos no carece en el resto, si se esceptuan unos pocos hombres que desconociendo el noble dictado del republicano, poseídos por móviles parciales i guiados por antipatías, no alcanzan a comprender la misión del verdadero e ilustrado patriotismo, i por esto con ningún orden de cosas se avienen. ${ }^{40}$

Lo interesante de este apoyo es que no se concentra únicamente en los vecinos de los cantones, sino que sirve como figura para representar el partido liberal como una persona de principios morales lo suficientemente aceptables para la opinión pública. Recordemos que la sensibilidad de la opinión en el discurso cotidiano radica en su forma de ser ante el público y en la vida privada. De esta manera, las comparaciones que se tenían del gobernador Cuéllar frente a la administración de Hoyos eran relativamente positivas, en función de que se le daba mayor prioridad al trabajo que éste había hecho en un año frente al trabajo con que, según la opinión de los vecinos de la provincia, Hoyos llevó sus varios años de ineficiente labor. De la misma forma se comparaba la situación religiosa que Cuéllar llevaba con visibilidad para la honra del partido, mientras que su antecesor no tenía gran aceptación por parte de los católicos,

[...] i al hablar sobre este punto debemos notar que el actual gobernador, hombre de severas costumbres, lo hemos visto cumplir con los preceptos de la Iglesia, i dar así un noble ejemplo al pueblo, mientras que el señor Hoyos cuando ocupaba el mismo puesto huía de toda ceremonia religiosa [...] ¿cómo pues conciliar estos hechos con los cargos de irreligiosidad que se hacen a los hombres del partido liberal ${ }^{41}$

Pero esta cuestión no sólo le acarreaba responsabilidad y éxito a Patrocinio Cuéllar, de igual manera eran reconocidos

40 "Ciudadano Presidente de la República", La Libertad 9, Tunja, junio 21, 1850, 3.

41 La Libertad 12, Tunja, julio 26, 1850, 3. 
que los méritos en la creación del Obispado de Boyacá se debían a la intervención de Alejo Morales, y de él había dependido el fortalecimiento de la religión católica en la provincia. Con este hecho, se hace más claro que los antagonismos clásicos sobre la adscripción de la iglesia católica al partido conservador no eran del todo claros y, por el contrario, las políticas liberales trataban de mantener, en un primer momento, relaciones estables con los representantes de la iglesia católica, y en general con la población tunjana.

Desde estos términos, la Sociedad (Democrática) de Instrucción Popular se afianzaba en el poder, en especial en un panorama bastante prometedor. Al transcurrir un año en el poder, tenían a cargo la gobernación con Cuéllar, se mantenía en el poder fiscal Alejo Morales y de igual manera Carlos María Gómez como ministro juez interino del Tribunal de Boyacá. En general, durante dicho año, se proyectaban a conseguir futuros cargos en las elecciones de 1850, en donde, como la mayor parte del partido liberal, apoyaban la candidatura de José de Obaldía a la vicepresidencia, pero en sus pretensiones regionales el cuadro de postulados estaba de la siguiente manera:

- Para Senadores: General Manuel María Franco y Miguel La Rota.

- Para Representantes: Juan Nepomuceno Rojas, Ignacio Pinzón, Antonio María Amézquita y Camilo Riva de Neira.

- Diputados a la Cámara de Provincia: José Niño, Antonio G. Franco, Manuel Mota López, José Primo Rojas, Miguel La Rota, Ramón Escovar, Cayetano Castillo, Rafael Angulo, Manuel Uribe, Hipólito Machado, Antonio María Amézquita y Vicente Azula.

- Juez Letrado del Cantón de Centro: Segundo Castiblanco.

De estos individuos se organizaba de nuevo el proyecto político, ya no sólo como un grupo de asociaciones, sino que se adscribían al partido liberal, constituido ideológicamente 
por el también boyacense Ezequiel Rojas, representante del Congreso de la República. Las políticas que se proyectaban desde este grupo de candidatos, y que eran parte constituyente de los intereses políticos de la Sociedad de Instrucción Popular, son las siguientes:

1. Que el Senador i los Representantes voten por el señor José de Obaldía para Viscepresidente de la República, en caso de que no sea electo popularmente, como seguramente sucederá.

2. Sostener la administración actual mientras que ella marche, como hasta hoy, por el sendero que le trazan la Constitución i las leyes.

3. Promover i sostener la reforma de la Constitución en el sentido más favorable al pueblo.

4. Sostener i defender la Relijion Católica, Apostólica, Romana, su culto i sus ministros.

5. Promover i sostener la abolición de la esclavitud.

6. Promover i defender la verdadera libertad de imprenta.

7. Procurar el ensanche del poder municipal.

8. Promover la perfecta organización de la Guardia Nacional i la completa eliminación del ejército permanente.

9. Procurar la más severa economía en los gastos públicos, i la disminución de contribuciones.

10. Promover i defender la libertad del comercio, la industria i de la instrucción ${ }^{42}$.

De esta manera se lleva a cabo un proceso visible de consolidación del liberalismo en las esferas de elección gubernamental, tanto de manera nacional como regional. Lo que se espera durante este primer año es la latencia de reagrupaciones y definiciones a favor y en contra de la

42 "Elecciones", La Libertad 11, Tunja, julio 12, 1850, 1. 
asociación liberal que se proyecta utópicamente como una fuerza lo suficientemente estable en el poder. Poco a poco los espacios y centros de instrucción se suman al fortalecimiento de la Sociedad.

\begin{abstract}
Al paso que todo lo que tiene color conservero, mengua lo liberal i progresa. El colejio provicial tiene más de cien jóvenes de exaltado patriotismo, sujetos a una severa disciplina, i entre ellos muchos de brillantes capacidades, estrema aplicación, i maneras cultas i agradables. La Sociedad Democrática tiene cerca de doscientos miembros, entre ellos figuran los hombres de más valer de la ciudad por su patriotismo, su instrucción, su honradez i sus recursos pecuniarios. $^{43}$
\end{abstract}

\title{
5. Conclusiones
}

Una de las implicaciones de los cambios políticos en la República de la Nueva Granada fue la formación de grupos de jóvenes políticos y abogados que permitieron ingresar durante la década de los cuarenta en el poder gubernamental, perfilándose para una continuidad política gracias a la estructuración de asociaciones que integraban a vecinos de la ciudad y ciudadanos en particular. Es decir, un grupo de hombres que se estructuraron como una élite con una ideología que integraba lo religioso, lo económico y lo cultural. De manera regional, se visualizó con esto una de las maneras como se fue configurando políticamente la Sociedad de Instrucción Popular en la capital de la provincia de Tunja. Esto permite además comprender que las acciones colectivas no son imitaciones de intereses homogéneos, sino una serie de prácticas heterogéneas que se entrecruzan desde lo concreto y lo genérico, más de una forma dialéctica y dinámica que de una manera sintética y estática.

La Sociedad de Instrucción Popular fue el producto de la consolidación de individuos que lograron tomar el gobierno de la provincia mediante la lucha por la afirmación de intereses personales y representaciones grupales. Este tipo de

$43 \quad$ La Libertad 5, Tunja, mayo 24, 1850, 4. 
organizaciones escapan de la literatura histórica tradicional de Tunja al comprobarse que no podrían partir únicamente de imaginarios o ideologías preconcebidas del liberalismo, sean autónomas o tomadas de procesos políticos internacionales. Sino que, por el contrario, existen aspectos de las asociaciones que se sustentan de propósitos interpersonales, de conflictos directos y desigualdades en el poder para la administración de los recursos del gobierno provincial. La derivación de estas implicaciones desde la comprensión histórica, radica en reconstruir la memoria de lo socio-político en cuanto a lo puramente "superficial", más allá de llevar a cabo una referencia esencialista de lo que significa ser o no liberal. En última instancia, es comprobar que aquellos procesos políticos son profundamente variables y dependen de la posición de los agentes en espacios determinados socioeconómicamente para conseguir beneficios específicos, son formas de asociación que explicitan estrategias, luchas y revanchas desde prácticas de asociación y disociación.

\section{Fuentes documentales}

Archivo General de la Nación (AGN). "Contra el Dr. Carlos González Ministro Juez del Distrito Judicial de Boyacá". Asuntos Criminales de la República: Sección República, 12. 1849. Fol. $885 \mathrm{v}$.

Biblioteca Nacional de Colombia (BCN). Estado Federal del Socorro Provincia de Tunja, Acta 2. Tunja: Impreso por José Ayarza, 1840. Fondo Pineda (FP) 469, Fol. 87.

Francisco J. de Hoyos a los habitantes de la provincia de Tunja. Tunja, 26 de mayo de 1841. FP 888. pza. 31.

. Francisco J. de Hoyos Gobernador de la provincia de Tunja por el gobierno lejítimo de la Nueva Granada. Santa Rosa de Viterbo: Impreso Por Vicente Baños, diciembre 17, 1840. BNC, Fondo Quijano 260. 
Francisco J. de Hoyos, Contestación a una carta Señores Doctores. Tunja, Junio 9, 1845. Tunja: Imp. por Vicente de Baños, 1845. FP 888. pza. 34.

Sr. Doctor Francisco José de Hoyos. Tunja, junio $1^{\circ}$ de 1845. Tunja, Imp. por Vicente de Baños, 1845. Fondo Pineda 873. Fol. 173r.

"Candidatura para la presidencia Jeneral Eusebio Borrero". El Oteador 5. Tunja, marzo 19, 1848, 2.

"Ciudadano Presidente de la República". La Libertad 8. Tunja, junio 1,1850 .

“Congreso". El oteador 3. Tunja, febrero 24, 1848, 4.

De Mosquera, Tomás Cipriano. Discurso del presidente provisorio de los Estados Unidos de Colombia, en la instalación de la Convención Nacional. Bogotá: Imprenta de Echeverría Hermanos, 1868.

"Editorial". La Libertad 1. Tunja, abril 1, 1850, 1.

"El 7 de marzo en la Nueva Granada". La Libertad 1. Tunja, abril $1,1850,3$.

El Labrador i Artesano 16, Bogotá, domingo 30 de diciembre, 1838, 60. Juan Nepomuceno Toscano, carta al Jefe Político de Tenza. Estado Federal del Socorro, octubre 12, 1840 [manuscrito]. BCN-FP, 873.

El Labrador i Artesano 17. Bogotá, enero 6, 1839, 65.

El patriota 2, Tunja, enero 15, 1838.

“Elecciones”. La Libertad 11. Tunja, julio 12, 1850, 1.

Gaceta oficial 1058. Bogotá, julio 1, 1849.

Gómez, Carlos María. Al público. Tunja, 1848. BCN-FP 815, pza. 9

Gómez, Carlos María. Al público. Tunja: Imp. de Vicente Baños, 4 de junio de 1842. Biblioteca Nacional de Colombia (BCN) Fondo Pineda (FP) 466. pza. 204 v. 
La Libertad 12. Tunja, julio 26, 1850. 3.

La Libertad 5. Tunja, mayo 24, 1850, 4.

"Lista de los Ciudadanos que concurrieron a la instalación de la Sociedad de Instrucción Popular en la capital de la provincia de Tunja”. Gaceta oficial 1089. Bogotá, diciembre 2, 1849, 550.

Manrique, Eloi. Espresión de agravios hecha en estrados contra la sentencia pronunciada en 1 a instancia, por el Dr. Manuel Restrepo Sarasti: en la acusación intentada contra el Dr. Alejo Morales, por infracción de constitución y leyes, abuso de autoridad, detención arbitraria, prevaricato y omisión en la persecución de los delincuentes. Bogotá: Imprenta de Jesús A. Cualla. 1845. BCN-Fondo Quijano (FQ) 313. pza. 18,13.

"Resultado de un denuncio contra los ministros de la corte suprema". Gaceta Oficial 1041, Bogotá, mayo 3, 1849: 162.

"Sociedad de Instrucción Popular". Gaceta oficial 1089. Bogotá, diciembre 2, 1849, 550 .

\section{Bibliografía}

Chapman Quevedo, Willian. "Sociabilidades y prácticas políticas en Popayán, 1832-1853”. Historia Caribe, V, 13, (2008): 179-207.

De Plaza, José Antonio. Apéndice a la recopilación de Leyes de la Nueva Granada. Bogotá: Imprenta del Neogranadino, 1850.

Escobar Rodríguez, Carmen. La Revolución Liberal y la protesta del artesanado. Bogotá: Fundación Universitaria Autónoma de Colombia, 1990.

Gaviria Liévano, Enrique. El liberalismo y la insurrección de los artesanos contra el librecambio. Primeras manifestaciones socialistas en Colombia. Bogotá: Universidad Jorge Tadeo Lozano, 2002.

González Bernaldo de Quirós, Pilar. "La sociabilidad y la historia política". Nuevo mundo, mundos nuevos (2008) [En ligne], Bibliothèque des Auteurs du Centre, González Bernaldo, Pilar, consulté le 09 mai 2014. URL: http://nuevomundo. revues.org/24082. 
González Escobar, Luis. Maestros y artesanos en la arquitectura de Medellín y Antioquia 1775-1932. Medellín: Universidad Nacional, Facultad de Arquitectura, 2008.

Guarín Martínez, Oscar. "La sociabilidad política: un juego de luces y sombras". Memoria y Sociedad 14, 29 (2010): 25-36.

Gutiérrez Sanín, Francisco. Curso y discurso del movimiento plebeyo 1849-1854. Bogotá: El Áncora Editores, 1995.

Jaramillo Uribe, Jaime. "Las sociedades democráticas de artesanos y la coyuntura política colombiana de 1848". En: La personalidad histórica de Colombia y otros ensayos. Bogotá: Biblioteca Básica Colombiana, Colcultura, 1977.

Loaiza Cano, Gilberto. Sociabilidad, religión y política en la definición de la nación. (Colombia 1820-1886). Bogotá: Universidad Externado de Colombia, 2011.

Tovar Borda, Jaime. Radicales, religionarios y artesanos, sociabilidad y política: Bogotá 1855-1870. Tunja: UPTC. 2005.

Uribe Urán, Victor M. Honorable Lives: Lawyers, Family, and Politics in Colombia, 1780-1850. Pittsburgh: University of Pittsburgh Press, 2000.

"Sociabilidad política popular, abogados, guerra y bandidismo en nueva granada, 1830-1850 respuestas subalternas y reacciones elitistas". Historia y Sociedad 9, (2003): 89-116.

."The Lawyers and New Granada's Late Colonial State". Journal of Latin American Studies, 27, 3 (1995): 517-549.

Vega Cantor, Renán. "Liberalismo económico y artesanado en la Colombia decimonónica”. Boletín cultural y bibliográfico, 22. (1990).

\section{Citar este artículo:}

Daniel Roberto Vega Torres, "Sociabilidad política liberal de Tunja: conflictos, utopías y distopías 1843-1851”, Revista Historia y Memoria No. 09 (julio-diciembre, 2014): 189-220. 